\title{
SEM MAIS - DECIDIR DESDE A LOUCURA
}

NOTHING ELSE - DECIDING FROM MADNESS

Piero Eyben

Universidade de Brasília

Brasília, Brasil

\begin{abstract}
Resumo
Tomando a epígrafe de Kierkegaard lançada por Jacques Derrida em seu "Cogito e história da loucura", digo, de sua leitura do texto de Foucault, o presente trabalho propõe discutir o instante da decisão, mais além do enigma, como instância última, aporética e no limiar do enlutamento. Desse modo, toda interpretação convergiria a um espaçamento da escritura, ao espaçamento que rompe a clausura e institui-se desde o segredo, desde a paixão do nome, como fica evidenciado pela textualidade de Mallarmé, Artaud, Rosa e Derrida.
\end{abstract}

Palavras-chave: decisão; loucura; aporia; desconstrução.

\section{Abstract}

Taking the epigraph of Kierkegaard launched by JacquesDerrida in his "Cogito and the history of madness", by his reading of the text of Foucault, this paper aims to discuss the moment of decision, beyond the enigma, as an ultimate aporia and on the threshold of mourning. Thus, any interpretation converge to aspacing of writing, the spacing that breaks the cloister and establish it self from the secret, since the passion of the name, as it is evidenced by the textuality of Mallarmé, Artaud, Rosa and Derrida.

Keywords: decision; madness; aporia; deconstruction.

\section{Résumé}

En prenantl'épigraphe de Kierkegaard prise par Jacques Derrida dans son "Cogito et l'histoire de la folie», sa lecture du texte de Foucault, cet essai a pour but de discuter l'instant de la décision, au-delà del'énigme, comme dernière instance, aporétique et sur le seuildudeuil. Ainsi, toute interprétation convergeraità un espacement de l'écriture, à l'espacement qui rompt la clôtureets'établie dès le secret, la passion du nom, tant qu'on le met en évidence par la textualité de Mallarmé, Artaud, Rosa et Derrida.

Mots-clés: décision; folie; aporie; déconstruction.

Sem mais, quero dizer, sem mais.

A economia do mais, ou daquilo que a mais quer dizer, logo, de sua verdade portada, trazida, carregada, postada e conduzida. Ademais, toda decisão corre um risco, um risco e uma prova de tornar-se indecidível. Ademais - algo que traduz o Jenseits de Freud, o Jenseits des Lustprinzips - espero, dizendo a um ti, tomar a decisáo em um como se, um como se que suplementa a lógica 
do como - do "estruturado como uma linguagem" - e, logo, do como tal que forma o sujeito. O sujeito como se aquele que - de modo soberano - se alimenta, se alimentasse mal, fosse, entâo, capaz de uma lei doméstica calculável, indivisível e originária. O sujeito da condição, do condicionante, do condicionado, muito aquém de toda distância possível ao outro, que permanece vindo, permanece sem morada, sem permanência, portanto. Ademais, mais além, para além dele, tu propóes a responsabilidade, o responder sem mais, o responder à questâo, à questão do quem, sem mais.

Assim, é tomando a epígrafe de Kierkegaard, a enxertia, lançada por Jacques Derrida em seu "Cogito et histoire de la folie", digo, de sua leitura do texto de Foucault, que pretendo propor discutir o instante da decisão, mais além do enigma, como instância última, aporética e no limiar do enlutamento. E, evidentemente, não apenas essa estrutura que Derrida percebe no campo entre loucura, decisão e Kierkegaard - o mesmo que 32 anos depois servirá para compor o estatuto aporético da responsabilidade diante do ato fundacional, sacrificial e de doação, por assim dizer, em Donner la mort-, mas também naquilo que penso olvidar aqui, nos nomes que se apagam do endereçamento. Digo que tomarei a epígrafe tomada de Kierkegaard para logo dizer que o texto de Derrida possui duas epígrafes, dois textos enxertados antes da discussão com Foucault, da discussão que será o fim durante ao menos nove anos da não-resposta do "arqueólogo". Assim, seja talvez, no endereçamento, "parce que je ne veux pas être seul, le seul à en parler après la mort de (...) sinon pour dire que cette ombre qui nous rendit l'un à l'autre invisibles pendant près de dix ans" (DERRIDA, 1996: 23). É o que resiste a Derrida, o que permanece resistindo desde a psicanálise como movimento da interpretação, e também como espaçamento que deixa a questão sofrer, que mantém certo gozo cruel no sofrimento - no "jouir à faire ou à laisser souffrir, à se faire ou à se laisser souffrir, soi-même, l'autre comme autre, l'autre et les autres en soi, moi, toi, il, elle, vous, nous, ils ou elles, etc." (DERRIDA, 2000: 13) - ao mesmo tempo em que o adia, o protela e o dá direito a acontecer. Deixo assim dois nomes em suspenso e pretendo dizer assim, quase sublevadamente. Na elipse de um texto outro, de um nome também ele outro e na preposiçáo que deixo de lado, espaçadamente. Seja talvez um como se da palavra, da loucura da palavra.

Kierkegaard, supraescrito na argumentação de Derrida, escreve "l'Instant de la Décision est une Folie". Assim, sem referência. Como que desde um título para fazer pensar os contornos da meditação cartesiana, o método foucaultiano e, logo, a desconstrução. Interessa-me, no entanto, não essa discussão, mas o que é possível escrutinar dessa escritura. No fundo, portanto e ademais, o que são o instante, a decisão e a loucura desde os quais decidimos. Ou melhor, dito de outro modo, como a decisáo pressupóe sempre uma loucura da prova, uma 
loucura do tempo e, por isso, demove todo aparato de temporalidade da crise, de tempo do próprio sentido. Escreves o escrutínio das cinzas, do nome, eis o impossível. Nesse sentido, a escritura - sempre tua, conativa - apenas pode ser justa, ajustada, se tomada desde sua heteronomia - de um nome que comporte os componentes não da constatação representacional, mas de seu aspecto poiético, da produção desde o sentido ao qual respondo - e, logo, desde seu estar em dissensão e dimensão de enunciados que são a própria performance da justiça. Derrida, anos após, retoma a sentença de Kierkegaard em um contexto totalmente diverso, em Force de loi. Permitam-me citar longamente:

[...] le moment de la décision, en tant que tel, ce qui doit être juste, il faut que cela reste toujours un moment fini d'urgence et de précipitation; cela ne doit pas être la conséquence ou l'effet de ce savoir théorique ou historique, de cette réflexion ou de cette délibération, dès lors que la décision marque toujours l'interruption de la délibération juridico- ou éthico- ou politico-cognitive qui la précède, et qui doit le précéder. L'instant de la décision est une folie, dit Kierkegaard. C'est vrai en particulier de l'instant de la décision juste qui doit aussi déchirer le temps et défier les dialectiques. C'est une folie. Une folie car une telle décision est à la fois sur-active et subie, elle garde quelque chose de passif, voire d'inconscient, comme si le décideur n'était libre qu'à se laisser affecter par sa propre décision et comme si celle-ci venait de l'autre (DERRIDA, 1994a: 58).

Como tal, como se. A justiça que está implicada em uma decisão precisa comportar o lugar do outro enquanto "violência irruptiva", como dirá Derrida. Há sempre algo que irrompe desse momento, desde o momento em que digo uma decisão ao outro, a decisão, que pode ser minha, de minha singular aparição, ao outro, do outro. $\mathrm{O}$ momento decisivo implica, logo, um necessário avanço temporal, um deslocamento que é a quebra da propriedade e do fim. O momento da decisão, sendo necessariamente urgente e precipitado, deve, ao mesmo tempo, compor seu aspecto finito desde as consequências do dever, do é preciso, de seus imperativos, muito anteriores ao momento em que se diz a decisão, muito posteriores ao instante que é esse da urgência. Uma decisão interrompe a deliberação (política-ética-jurídica) para, desde ela, fazer surgir - em demora e sofrente - o outro a quem a justiça se demanda, se pede em princípio. Essa interrupção precede até mesmo a deliberação - sempre já interrompida, desde já despida e furtada de seu sentido final -, tendo em vista que, ao ter iniciado uma deliberação, o pedido por uma decisão já implicaria sua loucura, sua precedência em um fazer-se cumprir o dever frente ao outro, à necessidade da promessa. Para "ser justa” - posicionar-se corretamente, então, diante do júri -, a decisão deve ser como tal, urgente e finita. Isso implica a noção de despesa e dispêndio do próprio regime jurídico. Na urgência da decisão pela justiça, o dizer decisório deve ser finito e declarado. No entanto, para que haja justiça na decisão, ela precisa sempre ser como se afetado desde o outro, pelo outro, em uma hiperbólica passi- 
vidade - palavra que traduz mal o déseuvrement (a 'in-operância', talvez) - que o deixa livre apenas para deixar-se "afetar por sua própria decisão". Nesse sentido, toda decisão é, em si, impossível. Ela é a urgência da justiça, que é "la chance de l'événement et la condition de l'histoire" (DERRIDA, 1994a: 61), que é, logo, a loucura de ter de, em sua incalculabilidade, comandar, acionar o cálculo.

Diria, sem demoras: a decisão responde ao outro. Sem sujeito. Sem mais. Quem responde precisa ser exapropriado por um responder a quem. O mesmo que se consome na loucura de sua ipseidade - de seu narcisismo infinito - apenas é capaz de uma figuração real, desde o real (da angústia), preso na mesma imagem do fora, de algo que se trancou mais distante, mais solitariamente deslocado daquilo que certa "sanidade" exigiria dele. Do um ao outro, infigurabilidade da representação, o impossível abarcar-se da decisão. Devo decidir pelo outro, diante dele, a ele. Esse é o imperativo antes do devir lei da moral, da calculabilidade de tudo o que náo é excessivo na responsabilidade. Logo, a decisão é, desde já, responsabilidade ao outro e, por isso, "on ne décide que là où c'est impossible" (DERRIDA, 1996: 47). Então, apenas desde esse sujeito que não existe como afirmação pronominal, como fundamento pronominal do chamado, do chamamento e do estar-fundadodesde-já. O justo desse sujeito é ele estar em uma neutralidade outra, em um outro que pertence a sua anterioridade do neutro do imperativo. A proposição "não se decide senão..." implica uma negativa-afirmativa, o próprio espaço da aporeticidade. O dom dessa proposição está justamente em sua impossibilidade, e também em seu ato frásico, se assim posso dizer. Da negação à restrição, o verbo da decisão cria o espaçamento desse comando, dessa ordem a qual a justiça faz sua força e aplicabilidade nos limites da autoridade mística. E, como bem definiu Aristóteles, "de fato, por ele próprio o ser não é nada, mas agrega àquilo que ele já significa alguma composição, a qual é impensável sem os componentes" (ARISTÓTELES, 2013: 7, 16b). A decisão não é senão desde sua incalculabilidade, de sua aporia e loucura; no entanto, ela não é senão no comando por um artefato calculável, por aquilo em que se estipula como normatividade. Digo, a justiça que vem da decisão permanece sempre vindo, chegante, em restância. Não sendo ela mesma justamente o que pode ser, em sua possibilidade de ser, a justiça permanece impossibilitada como toda decisão. Violência irruptiva que produz seu por-vir como excesso compositivo, como dar agregação - acolhimento - ao sentido entregue às ferramentas da própria linguagem. Sem mais, o outro a que respondo faz prova do indecidível que, sendo a "expérience de ce qui, étranger, hétérogène à l'ordre du calculable et de la règle, doit cependant - c'est de devoir qu'il faut parler - se livrer à la décision impossible en tenant compte du droit et de la règle" (DERRIDA, 2004a: 53), assombra toda decidibilidade narcísica, subjetiva e, logo, carno-falo-logo-centrada. 
O dever, ao qual se deve decidir senão, trata de um dever do lugar. Então se trata de lugar - do espaço inominável da khôra - em que o impossível se arrisca como referência à justiça. $\mathrm{O}$ senão da decisão ocorre là où. Algo passivo, "voire d'inconscient". Não pertencendo apenas à sintaxe padrão do francês de Derrida, o là où remete-se imediatamente a esse de Lacan, quando do desmembramento do cogito cartesiano nos Écrits: "Je pense à ce que je suis, là où je ne pense pas penser” (LACAN, 1966: 517). O lugar em que não se pensa, ali o ser do je suis (daquele que diz que pensa) faz a dúvida voltar a ele. Trata-se de lugar entáo. No entanto, é do lugar do inconsciente que precisamos falar, para essa decisão louca, o lugar da Coisa freudiana: "wo es war, soll ich werden”. É Haroldo de Campos, em Afreudisíaco Lacan, quem vai produzir uma analítica da tradução dessa frase inconcebível, impossível:

WO ES WAR, SOLL ICH WERDEN

VÔ S V-R ZÓ V-R = transcrição ressaltando em port. o jogo das figuras fônicas do alemão.

WHERE THE ID WAS, THERE THE EGO SHALL BE = tradução inglesa criticada por Lacan: Freud não disse das Es, nem das Ich (EC I, 226).

LE MOI DOIT DÉLOGER LE ÇA = tradução francesa repelida por Lacan (EC I, 227-228, no 4):

I MUST COME TO PLACE WHERE THAT (ID) WAS = trad. para o ingl. em The Yale French Review, 36-37,1966.

DONDE ESTUVO ESO, TENGO QUE ADVENIR = trad. para o espanhol por Tomás Segovia (in: J. Lacan, Lectura estructuralista de Freud, Siglo XXI, México, 1971).

LÁ ONDE ERA ISSO, ME É PRECISO CHEGAR = trad. brasileira, ESC. 255.

LÀ OŨ FÛT ÇA, IL ME FAUT ADVNENIR = trad. de Lacan em Écrits, "L'instance de la lettre...», p. 524.

LÀ OÙ C'ÉTAIT (S'ÉTAIT), C'EST MON DEVOIR QUE JE VLENNE À ÊTRE $=$ trad. de Lacan (EC I, 227).

(...)

LÀONDE ISS'ESTAVA DEV'EUREI DEVIR-ME (CAMPOS, 2010: 237-238).

Das multiplicidades dessas soluçóes tradutórias, restam o dever do lugar em que isso deve ser ou por-vir a ser. Trata-se então do impossível. O próprio "làonde" torna-se - devém - figura do impossível. A decisão, perpassada por seu dever tornar, faz do eu um espaço modalizado de tempos que saem do rastro do próprio inconsciente à promessa do eu. "Não se decide senão lá onde isso é impossível", outra possibilidade de traduzir, em excesso a sentença de Derrida que resiste à interpretação. O isso impossibilitado faz de seus rastros (wo es war) um lançamento do sujeito - naquilo que ele tem de jet, como também dirá Derrida a Nancy - mais além de seu assujeitamento à precipitação deliberativa a qual a decisão poderia, em princípio, nortear-se. Sem mais, a justiça trata então do impossível, faz prova de sua indecidibili- 
dade, quando do dever, o eu assume sua responsabilidade do outro. Daqui, é Freud o impossível. Desde sua especulação, Derrida propóe, analisando sua retórica, que "pas de Weg sans Umweg: le détour ne survient pas au chemin, il le constitue, même il le fraye" (DERRIDA, 1980: 304). O espaço não de interiorização, introjeção, encarnação, mas de decisão lançada à espectralidade não de uma Gegebenheit heideggeriana (do Sein und Zeit), de sua presença já dada como sentido à compreensão, mas de uma responsabilidade infinita pelo outro a qual não se pode deixar morrer. Digo, não há outro senão desde o absolutamente outro sendo todo e qualquer outro.

A segunda epígrafe de Derrida no ensaio sobre Foucault, que até agora adiei, pertence a Joyce e diz: "N'importe, c'était terriblement risqué, ce livre. Une feuille transparente le sépare de la folie (J. JOYCE, à propos d'Ulysse)". A fortuna e o acaso do acontecer desse livro. A metáfora de Joyce é forçosamente importante: "uma folha transparente o separa da loucura". Arriscado o dever tornar-se do livro que se mantém a salvo por uma folha transparente. Ainda representativo, o Ulysses é capaz de manter o sentido dentro de suas dinâmicas metafóricas. Isso não ocorrerá com o Finnegans Wake, no qual, poderíamos dizer, uma folha transparente o separa da realidade. O sujeito da psicose assombrosamente mantido no lugar da coisa. Inúmeras poderiam ainda ser as discussōes acerca da possibilidade desse texto fazer elo, constituir-se como espaço de cura ou sanidade - prefiro manter a crise da loucura. No entanto, vale ressaltar a extensão a qual nos propôs Lacan ao pensar o sujeito da psicose em sua relação com a linguagem (e, logo, com o inconsciente): "alors que ce dont nous voyons témoigner le sujet, c'est effectivement d'un certain virage dans le rapport de langage, dans quelque chose qu'on peut appeler dans l'ensemble «une érotisation» ou une passivation, ou une certaine façon de subir dans son ensemble le phénomène du langage, le phénomène du discours" (LACAN, 1981: 237). Faz sofrer sua passividade e sua erótica. A linguagem torna-se algo outro em que o esquecimento - o primeiro esquecimento de Joyce - vem a tornar-se o cerne de sua lembrança, isto é, a literatura como força do decidir-se desde a loucura.

A folha arriscada - seu risco forçosamente ao acaso, ao acaso inventado faz do texto a própria corrupçáo, ou melhor, o texto arrisca o ser louco da corrupção. A loucura da criação - a loucura dos filhos de Elohim, como propóe o subtítulo do conto-poema de Mallarmé, Igitur - constrói um tempo em que o eu, na meia-noite imemorial, "aimerais rentrer en mon Ombre incréée et antérieure, et dépouiller par la pensée le travestissement que m’a imposé la nécessité, d'habiter le coeur de cette race (que j'entends battre ici) seul reste d'ambiguïté" (MALLARMÉ, 1998: 850). Dessa anterioridade despojada, o poema se faz na loucura do tempo. Esse é o ato, o ato como o horror diante do espelho, que se consuma à admissão de sua negação do acaso, onde "son moi se manifeste par ceci qu’il reprend la Folie”, ou ainda, “- Alors il conçoit qu'il y 
a, certes, folie à l'admettre absolument: mais en même temps il peut dire que, par le fait de cette folie, le hasard étant nié, cette folie était nécessaire. À quoi? (Nul ne le sait, il est isolé de l'humanité)" (MALLARMÉ, 1998: 840). É apenas desde a loucura do acaso que o risco do texto em não se fazer se consuma, se conclui e, logo, projeta-se como infinito. $\mathrm{O}$ espaço aqui de sua finitude decisória reduz o livro ao infinito, e, com isso, o acaso, como toda sombra lançada desse que decide a quem, lança-se como "l'ombre disparut dans les ténèbres futures" (MALLARMÉ, 1998: 858).

O texto escritural ainda pode produzir-se como figura da loucura, pode, por extensão, figurar a loucura. Todos conhecem o conto "Sorôco, sua mãe, sua filha”. Todos conhecem a estória. A entrega à loucura. Sorôco leva a mãe e a filha para a estação de trem onde serão levadas ao hospício. No trajeto, elas cantam uma música estranha - "a cantiga não vigorava certa, nem no tom nem no se-dizer das palavras" (ROSA, 1988: 19) - e, logo após as ter deixado para trás, Sorôco inicia uma música que acompanha toda a cidade, todo o sentido da habitação se reconstrói para o conto. O que Rosa faz, então, é de um só espanto de escrita. $\mathrm{Na}$ entrega das mulheres ao trem, um parágrafo de uma só palavra quebra o conto em dois, desiguais e com focos narrativos distintos. O parágrafo possui apenas o nome de Sorôco, que segue no seguinte com um discurso indireto livre. Ele, agora entregue "ao sofrer o assim das coisas, ele, no oco sem beiras, debaixo do peso, sem queixas, exemploso" (ROSA, 1988: 21), como escreve Rosa, produzindo a abertura do nome de seu personagem: o Senhor Oco. O espaço sem beiras, o espaçamento sem margens da loucura que "ia até aonde que ia aquela cantiga" (ROSA, 1988: 21). Lá onde o canto se desfaz da racionalidade, despede-se do peso do pensamento ordenado da narrativa, por uma sintaxe que corrompe o sentido dado, o sentido como datividade e compreensão. Aqui, o canto é uma forma. O canto é a forma de ocar o sentido em que "se foi, o de sempre", a continuação daquilo que não é senão remetimento, memória do "a gente" que conduz a essa casa de ninguém. A figuração desse sentido que se esvai - "assim num excesso de espírito, fora de sentido" - implica a necessidade de um deslizamento na qual a relação se faz como inscrição rasurante, como restância desses corpos que, em sua ausência, exigem o luto impossível daquilo que é o amor da passibilidade, do sem recurso. O nenhures da decisão, sem mais.

Cabe então perguntar, desde essa responsabilidade, como o sentido se faz na loucura? Logo, na decisão? Como o instante que "dans l'épreuve de ce qui reste à décider" (DERRIDA, 1994b: 33) pode produzir um tempo que é o próprio da decisão como atravessamento da indecidibilidade suspensa ou suspendida? Acolhimento e resposta à distância. $\mathrm{O}$ instante é de cinzas, de incineração. A possibilidade de se apagar toda a memória, de eliminar tudo pelo fogo. Não aquilo que possa ser o sacrificial, mas o atear que faz sobrar nada mais que 
cinzas. Em Feu la cendre, as cinzas não estão mais lá. Ou ainda, Derrida diria, à maneira de diálogo: "Le nom de cendre est une cendre encore de la cendre même" (DERRIDA, 1987: 33). Aquilo que não deixa rastros, il y a là cendre. Tendo desaparecido completamente, restam apenas aí - o lugar da decisão e da loucura - cinzas. O rastro, para além de seu modo de impressáo, de sua marca degenerativa, é marcado (não uma marca) sobretudo por sua possibilidade em ser apagado, destruído, incinerado. É assim inominável toda cinza que resta, logo, toda decisão que permanece a decidir, que resta como uma frase que resta por vir. É, então, que o texto não apenas se abrindo à interpretação, abre-se à loucura, à decisão que, no fundo, torna-se, para tomar uma metáfora de Derrida, uma loucura da promessa, um espaço da aporia se fazer como aquilo que "donne ou promet la pensée du chemin, provoque à penser la possibilité même de ce qui reste encore impensable ou impensé, voire impossible" (DERRIDA, 1988: 129-30). A loucura do texto promete - bem que é sempre o acontecer da promessa - e vela toda disjunçâo que do literário provém como aporia: lá onde o outro decide do outro. Se a incineraçáo pode ser compreendida como forma de apagar o rastro daquilo que é colocado na posição de guardar aquilo que foi escondido, recalcado, essa experiência da perda total do rastro, da perda da memória, apenas força a morte como loucura última (como proporá Blanchot) ou ainda a "condition violente de la connaissance ou de l'action" (DERRIDA, 1994a: 131) que provém da decisão sem decisão, da desconstruçáo como texto que corrompe louco, estranhado de tudo aquilo a quem posso decidir. Como diz de Artaud, Jean-Luc Nancy: "il n'y a pas ce qui ne peut pas être. Nous regardons ce qui ne peut pas être, ce qui n'a pas pu être là et ce qui n’a pas cru y être" (NANCY, 2006: 15). Ou ainda o próprio, em Suppôts et suppliciations:

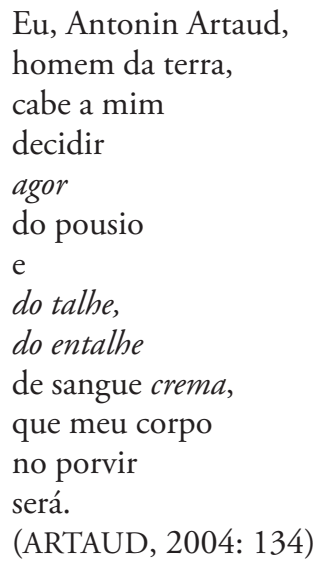

Disso que está por vir, a promessa e a decisão constituem-se como responsabilidade. Sobrevivência e sobre-escritura. Sem egologia ou termos do mero 
decidível. Sem mais, decidir desde a loucura ou ainda sem mais decidir desde a loucura. Dos valores que pertencem à esfera jurídica, a indecidibilidade permanecerá como condiçấo - lutuosa e impossível, incinerada - de fazer prova à toda resposta urgente, à toda interpretação imediata e, é óbvio, no campo de sua língua performática, decidir-se desde o outro, desde isso que enlouquece toda pergunta, toda demanda, mesmo a de amor, em cinzas de sentido.

Arrisquei tudo. Arrisquei a primeira palavra de um endereçamento. Lá a decisão, à luz do dia, logo, à loucura. Narro e arrisco tudo ao escrever-te. Uma imagem e o envio, envio-te sem decisão, sem lugar, alhures.

A ti. Até o fim.

\section{Referências bibliográficas}

ARISTÓTELES. Da interpretação. Ed. bilíngue. Trad. José Veríssimo Teixeira da Mata. São Paulo: UNESP, 2013.

ARTAUD, Antonin. Suppôts et suppliciations. Ed. Évelyne Grossman. Paris: Gallimard/ Quarto, 2004.

CAMPOS, Haroldo de. O segundo arco-íris branco. São Paulo: Iluminuras, 2010.

DERRIDA, Jacques. États d'âme de la psychanalyse. L'impossible au-delà d'une souveraine cruauté. Paris: Galilée, 2000. . Résistances de la psychanalyse. Paris: Galilée, 1996. . Force de loi. Le «Fondement mystique de l'autorité». Paris: Galilée, 1994a. . Politique de l'amitié suivi de l'oreille de Heidegger. Paris: Galilée, 1994b. . Mémoires: pour Paul de Man. Paris: Galilée, 1988. . Feu la cendre. Paris: Des Femmes, 1987. La cartepostale: de Socrate à Freud et au-delà. Paris: Aubier-Flammarion, 1980.

LACAN, Jacques. Le séminaire, livre III, Les psychoses. Paris: Seuil, 1981. . Ecrits. Paris: Seuil, 1966.

MALLARMÉ, Stéphane. «Igitur ou la folie d'Elbehnon». In: MARCHAL, Bertrand (Ed.).CEuvres Complètes I. Paris: Gallimard/Pléiade, 1998.

NANCY, Jean-Luc. «Le visage plaqué sur la face d'Artaud». In: FAU, Guillaume (Dir.). Antonin Artaud. Paris: Bibliothèque Nationale de France/Gallimard, 2006.

ROSA, João Guimarães. Primeiras estórias. Rio de Janeiro: Nova Fronteira, 1988.

Piero Eyben é Professor Adjunto 3 de Teoria da Literatura na Universidade de Brasília. Pesquisador de Produtividade do CNPq. Poeta e Tradutor. Coordena o Grupo de Pesquisa Escritura: Linguagem e Pensamento. Autor de Escritura do retorno: Mallarmé, Joyce e Meta-signo, Ocos e Voo de rapina; organizou os volumes Derrida, escritura \& diferença no limite ético-estético (coOrg. Fabricia Walace Rodrigues), Demoras na aporia: bordas do pensamento e da literatura, Pensamento intruso: Jean-Luc Nancy \& Jacques Derrida; além disso traduziu textos de Nancy, Derrida e Joyce. 